\title{
COORDENADORES PEDAGÓGICOS: TRAJETÓRIA, COMPETÊNCIAS E RESPONSABILIDADES
}

\author{
COORDINADORES PEDAGÓGICOS: TRAYECTORIA, HABILIDADES Y \\ RESPONSABILIDADES
}

\author{
PEDAGOGICAL COORDINATORS: TRAJECTORY, SKILLS AND \\ RESPONSABILITIES
}

Angelica Annunciação da SILVA ${ }^{1}$

Resumo: Este artigo de cunho bibliográfico possui como objetivo analisar como acontece o trabalho do coordenador pedagógico dentro da escola, desde seu surgimento até os dias de hoje. Percebe-se com a pesquisa que ser coordenador pedagógico requer, além de formação acadêmica, uma série de outros atributos, como por exemplo ser mediador, incentivador, problematizador, colaborador, entre outros. É importante que ele planeje e priorize suas ações enquanto formador e articulador do projeto político-pedagógico da escola para não se perder ao logo do caminho, estando apenas a serviço de urgências e emergências da escola. $\mathrm{O}$ estabelecimento de uma relação de confiança com os professores também é fundamental para que o trabalho pedagógico flua da melhor maneira possível, podendo resultar em uma educação de qualidade.

PALAVRAS-CHAVE: Coordenação. Professores. Escola.

RESUMEN: Este artículo bibliográfico tiene como objetivo analizar cómo se realiza el trabajo del coordinador pedagógico en la escuela, desde su surgimiento hasta la actualidad. De la investigación se puede ver que ser un coordinador pedagógico requiere, además de la formación académica, una serie de otros atributos, como ser un mediador, animador, problematizador, colaborador, entre otros. Es importante que el planifique y priorice sus acciones como formador y articulador del proyecto político-pedagógico de la escuela para no perderse en el camino, estando solo al servicio de las urgencias y emergencias de la escuela. El establecimiento de una relación de confianza con los maestros también es esencial para que el trabajo pedagógico fluya de la mejor manera posible, lo que puede resultar en una educación de calidad.

PALABRAS CLAVE: Coordinación. Maestros. Escuela.

ABSTRACT: This article of bibliographic nature aims to analyze how the work of the pedagogical coordinator in the school happens, since its emergence until today. It can be noticed from the research that being a pedagogical coordinator requires, in addition to academic formation, a series of other attributes, such as being a mediator, encourager, the

${ }^{1}$ Secretaria Municipal de Educação (SME), São Paulo - SP - Brasil. Coordenadora Pedagógica na Prefeitura Municipal de São Paulo. Mestrado em Ciências da Educação (UCP) - Paraguai. ORCID: https://orcid.org/00000002-4998-8182. E-mail: angelica_annun@hotmail.com

RPGE- Revista on line de Política e Gestão Educacional, Araraquara, v. 25, n. 1, p. 38-51, jan./abr. $2021 . \quad$ e-ISSN:1519-9029 DOI: https://doi.org/10.22633/rpge.v25i1.13983 
one who questions, collaborator, among others. It is important that the coordinator plans and prioritizes his actions as an educator and articulator of the school's political-pedagogical project so as not to get lost along the way, being only at the service of the school's urgencies and emergencies. The establishment of a trusting relationship with teachers is also essential for the pedagogical work to flow in the best possible way, which can result in quality education.

KEYWORDS: Coordinator. Teachers. School.

\section{Introdução}

De acordo com Almeida e Placco (2006), uma escola só é caracterizada como tal porque nela se concentram docentes e estudantes. Estes docentes formam um grupo que está a todo momento planejando, replanejando e tomando decisões acerca do que e como será ensinado aos estudantes e mesmo considerando a individualidade de cada um, eles necessitam ser liderados pelo Coordenador Pedagógico que é a figura que vai compartilhar com eles as responsabilidades que compõem o processo de ensino e aprendizagem e vai "possibilitar a construção do grupo, para desenvolver um trabalho coletivo rumo à superação das fragmentações hoje comuns nas escolas" (ALMEIDA; PLACCO 2006, p. 27).

O presente artigo de cunho bibliográfico possui como objetivo analisar como acontece o trabalho do coordenador pedagógico dentro da escola, desde seu surgimento até os dias de hoje.

O coordenador pedagógico é aquele que prevê, articula, media e avalia as ações pedagógicas da escola com e para o professor. De acordo com Almeida e Placco (2011), cabe à Coordenação Pedagógica levantar questões junto ao professorado, levá-los a reflexões sobre sua prática pedagógica em sala de aula. As autoras ressaltam ainda que o Coordenador Pedagógico é aquele que participou da elaboração e/ou adaptação da proposta pedagógica, podendo assim dar novos significados à prática educativa da escola e à prática pedagógica dos professores. Segundo Vasconcelos (2011), o professor Coordenador Pedagógico está sempre atento às necessidades dos docentes, ele os acolhe, escuta, subsidia, interage e questiona, provoca e problematiza as questões relacionadas às práticas de sala de aula, mas, isso nem sempre foi assim.

Por muitos anos a função do Coordenador Pedagógico era tida como aquela que tinha como objetivo "vigiar", verificar pura e simplesmente se o professor estava cumprindo com sua obrigação (VENAS, 2012). Surgida da Supervisão Pedagógica e presente nos cursos de Pedagogia, a coordenação pedagógica era representada pela figura de um adulto que tinha a 
função de "supervisionar" atividades que incluíam crianças, tal função existe antes do surgimento das escolas formais. $\mathrm{Na}$ Antiguidade, essa "função supervisora" ocorria "através dos cuidados e observações dos adultos em relação às crianças e jovens, nas comunidades primitivas” (VENAS, 2012, p. 01). Já na Grécia, o pedagogo era o profissional encarregado da função supervisora, era ele quem levava as crianças ao local reservado para a aprendizagem. Entretanto, com o passar do tempo, o pedagogo se transformou no próprio educador, que tinha a função de ensinar as crianças.

Quando a ideologia industrial, que primava pela razão técnica, extinguindo qualquer mediação da razão em relação à realidade que vinha a partir da experiência sensorial, começou a se instaurar, nem a escola foi poupada. A supervisão escolar que, naquele momento, se esforçava para libertar-se da concepção fiscalizadora e adentrar outra concepção mais integradora e coordenadora, não conseguiu avançar (VENAS, 2012).

O curso superior de Pedagogia surgiu no ano de 1939 e, de lá para cá, foi tendo que se adequar e readequar em conformidade com o momento histórico vivido pelo país, sendo esquecida, assim, a identidade do pedagogo. Ainda hoje, continuam acontecendo adequações na grade curricular do curso, algumas vezes devido ao mercado de trabalho, outras por razões da própria área de conhecimento (VENAS, 2012).

No passado, depois de formado pedagogo, o profissional tinha duas possibilidades de trabalho dentro da escola: dentro ou fora da sala de aula. Entretanto, as atividades nãodocentes não tinham um regulamento que as atendesse. Então, a formação desses profissionais ocorria na prática da função, assim foi se delineado o perfil dos pedagogos em questão. Naquela época, termos como "coordenação pedagógica", "inspeção escolar" e até mesmo "habilitação" não existiam formalmente, apenas nas escolas. Isso mostra que o trabalho não-docente surgiu antes mesmo de uma certificação da função (VENAS, 2012).

No que diz respeito à definição do papel do Coordenador Pedagógico, Vasconcellos (2007) nos alerta que sua imagem e função continuam associadas à do supervisor. Por conseguinte, o autor traz uma definição do que vem a ser Supervisão Pedagógica:

A supervisão não é (ou não deveria ser) fiscal de professor, não é dedo-duro (que entrega os professores para a direção ou mantenedora), não é pombo correio (que leva recado da direção para os professores e dos professores para a direção), não é coringa/tarefeiro/quebra galho/salva vidas (ajudante de direção, auxiliar de secretaria, enfermeiro, assistente social, etc.), não é tapa buraco (que fica "toureando" os alunos em sala de aula no caso de falta de professor), não é burocrata (que fica às voltas com relatórios e mais relatórios, gráficos, estatísticas sem sentido, mandando um monte de papéis para os professores preencherem - escola de "papel"), não é gabinete (que está longe da prática e dos desafios efetivos dos educadores), não é dicário 
(que tem dicas e soluções para todos os problemas, uma espécie de fonte inesgotável de técnicas, receitas), não é generalista (que entende quase nada de quase tudo) (VASCONCELLOS, 2007, p. 86-87).

O fato é que escola é o local onde se aprende uma série de saberes. Lá, "as pessoas não escolhem seus pares ou colegas, porém, se reúnem com o objetivo de trabalharem juntas durante um período de vida delas" (AMADO; GOUVEIA, 2012, p. 83). É na escola que se amplia a possibilidade de aprendizagens e interações presentes dentro e fora da sala de aula.

Entretanto, também é lá que, em todo momento, se está envolto em urgências e emergências de toda ordem, é aí que se insere a figura do Coordenador Pedagógico. Este cotidiano atribulado se mostra como um dos responsáveis pela falta de tempo e foco do Coordenador Pedagógico, "imprimindo uma rotina caótica, centrada no atendimento aos alunos e a outras demandas" (AMADO; GOUVEIA, 2012, p. 83).

De acordo com as autoras supracitadas, dentre essas demandas estão: atendimento telefônico; atendimento aos professores; reunião com diretor; conversa com estudantes; orientação aos familiares; substituição de docentes; solicitações do sistema; acompanhamento da entrada e saída dos estudantes; organização da classe; sanções disciplinares entre outras coisas.

Desse modo, torna-se complicado para o Coordenador Pedagógico executar o trabalho que de fato lhe cabe e é por isso que ele tem de se organizar, para que sua rotina não se resuma em "apagar incêndios", mediar situações de conflitos para com professores, familiares e estudantes. A questão é que, muitas vezes, nem o próprio Coordenador sabe ao certo o que de fato é ou não sua atribuição. Isso se deve a "uma instituição que não tem clareza da sua função social nem uma cultura de formação permanente" (AMADO; GOUVEIA, 2012, p. $85)$.

\section{Metodologia}

A pesquisa foi realizada a partir de análise bibliográfica em fontes referenciadas neste artigo, como: Placco (2011), Vasconcellos (2004), Amado e Gouveia (2012), entre outros que tecem algumas discussões sobre qual a função do Coordenador Pedagógico e a importância de suas intervenções no trabalho que os docentes realizam com os estudantes nas escolas. Não houve coleta de dados em locais físicos, tampouco estudo de casos, algo que seria de grande relevância e traria possibilidade de aprofundamento do tema. Para fundamentar este trabalho, buscou-se os conceitos definidos pelos autores supracitados, juntamente com reflexões e 
experiências da autora do presente artigo, discutindo-os de forma a elevar e reconhecer a importância de tal temática dentro da gestão escolar.

\section{Da supervisão escolar à coordenação pedagógica}

$\mathrm{Na}$ década de 1980, com o movimento "Diretas já" e com a promulgação da Constituição Federal de 1988, as pessoas se sentiam mais livres para irem em busca de seus direitos e conquistas sociais, passando a aceitar cada vez menos as práticas autoritárias. A Supervisão Escolar começa então a se tornar inadequada, já que um novo cenário econômico e político começa a ser desenhado. Então, em meados de 1980, alguns estados já começam a utilizar o termo "Coordenador Pedagógico" para nomear a figura que seria responsável pela garantia da qualidade educacional e da aprendizagem (VENAS, 2012), situação esta que se define melhor a partir da Lei de Diretrizes e Bases da Educação Nacional, Lei nº 9394/1996 (BRASIL, 1996).

Ainda na década de 1990, nas escolas estaduais de São Paulo (SP), criou-se o cargo de Professor Coordenador Pedagógico (PCP), cuja formação era em licenciatura e não necessariamente Pedagogia. Segundo Fernandes (2009), a função de PCP é ocupada por um professor que, eleito por seus pares, passa a coordenar e acompanhar o trabalho pedagógico da escola. Nesta proposta desenvolvida no estado de SP para a eleição do PCP deveria se levar em consideração as dimensões política, técnica e pedagógica. Entretanto, os professores escolhidos, eram aqueles que possuíam melhor relação interpessoal com o grupo de professores. Assim, por vezes, o que se tinha eram PCP inseguros e envoltos pela burocratização. Ainda sobre este cenário, Fernandes (2009, p. 4) afirma que,

\footnotetext{
Durante a análise desse contexto de criação da função de PCP, algumas questões nos levaram a uma investigação mais ampla. Estaria a criação da função ligada especificamente aos momentos de reformas educacionais recentes? Em outros cenários políticos, a função também se faria necessária? Por que a função, reivindicação histórica da categoria docente, foi incorporada ao pacote de reformas neoliberais? Qual a profissionalidade presente no trabalho do PCP? Com base nestas questões, passamos a trabalhar com a hipótese de que a função de Professor Coordenador Pedagógico foi incorporada às reformas educacionais atuais mais como um mecanismo de controle do que como uma função de articulação do trabalho coletivo, essa sim uma bandeira progressista.
}

Consequentemente, ao invés de ser um articulador do trabalho pedagógico desenvolvido na escola, o PCP tinha a função de receber e implementar pacotes prontos das reformas educacionais (VENAS 2012). 
Silva (2002) afirma que é uma exigência do Banco Mundial, agência financeira internacional sem fins lucrativos, da qual o Brasil faz parte desde 1993, que para implantação de projetos educacionais deveria haver:

o aumento de tempo escolar, a ampliação da duração do ciclo escolar, o aumento da capacidade de aprendizagens dos alunos, o apoio à educação pré-escolar, a melhoria do ambiente de sala de aula, o apoio aos sistemas de saúde e de nutrição, a melhoria da capacitação dos docentes, a maior capacitação em habilidades pedagógicas e incrementos para ensinar, a reestruturação administrativa e organizacional com desmembramento do sistema, o desenvolvimento das competências administrativas, criação do sistema de avaliação por desempenho, o provimento de sistemas de informações que contemplem eficiência organizacional, a persuasão dos pais acerca do valor da educação e a mobilização da comunidade para proventos econômicos (p. 83).

Vê-se que, assim, a grande influência do Banco Mundial na "formulação das políticas educacionais foi definindo uma forma de pensar sobre os elementos que organizam a vida escolar" (VENAS, 2012, p. 83). Todas essas exigências foram alimentando e reforçando o sistema capitalista e o ideal neoliberalista. Desse modo, também o Coordenador Pedagógico muitas vezes assumia essa prática na escola, sendo um controlador das atividades pedagógicas, além de exercer funções que fugiam da sua verdadeira atribuição.

\section{Atribuições do coordenador pedagógico}

Tendo a clareza de sua função, o Coordenador Pedagógico consegue organizar o tempo conforme suas obrigações. Para tanto, é importante que ele se reconheça enquanto formador e articulador das ações educativas coletivas da escola. No entanto, não é sozinho que o coordenador muda a direção do seu trabalho. É coletivamente, com a organização e definição dos papéis e funções dos profissionais que compõem a instituição, de forma colaborativa que se dará essa mudança de paradigma.

Amado e Gouveia (2012) propõem uma lista com oito atribuições que consideram ser do Coordenador Pedagógico:

1. Reunião de formação - o foco desta reunião está na reflexão sobre as práticas realizadas em sala de aula e seu objetivo é encontrar respostas para questões pedagógicas que o grupo de professores enfrenta. "Os estudos e planejamentos podem ser feitos em duplas ou pequenos grupos, dependendo dos conteúdos, dos objetivos e das necessidades dos professores" (AMADO; GOUVEIA, 2012, p. 86). Também se 
faz importante o acervo a ser utilizado pelo Coordenador Pedagógico nessas discussões.

2. Observação e acompanhamento do trabalho docente - uma das ferramentas para a melhora da prática pedagógica é o acompanhamento da sala de aula, pois é lá que se torna concreta toda discussão formativa que ocorre na escola. Entretanto, alguns Coordenadores Pedagógicos ainda encontram resistência por parte dos professores para a realização desse trabalho. Desse modo, é fundamental que, no início, os professores se ofereçam para terem suas aulas observadas. Após a observação, se faz necessário que o Coordenador dê uma devolutiva para o professor a respeito do que foi observado, podendo também transformá-la em foco para uma reunião de formação. "Nesses momentos, é essencial o professor compartilhar com os colegas as observações que fez da própria aula e as devolutivas recebidas do $\mathrm{CP}$ antes de este tecer seus comentários" (AMADO; GOUVEIA, 2012, p. 87).

3. Acompanhamento - o Coordenador Pedagógico pode acompanhar as atividades docentes por meio da análise de projetos, planos de ensino e de aula, sequências didáticas, cadernos de alunos, atividades avaliativas, entre outros. Almeida e Placco (2012) ressaltam que o Coordenador Pedagógico acordará previamente com cada docente se irá tratar disso individualmente ou durante a formação permanente com todos os professores.

4. Planejamento da formação - para que sua função de formador seja realizada a contento, se faz necessário que o Coordenador revisite periodicamente seu projeto de formação, montando pautas formativas para cada reunião. Segundo Almeida e Placco (2012), para que isso ocorra, o mesmo precisa estudar e pesquisar autores e documentos que convirjam com o objetivo a ser alcançado na reunião.

5. Organização do acervo - por acervo entende-se o Projeto Político-Pedagógico da escola, os planos de ensino e de aula, portfólios, avaliações entre outros. Estes "devem estar sempre em ordem para ser consultados e servirem para a montagem do acervo e da memória pedagógica da instituição" (AMADO; GOUVEIA, 2012, p. 89-90).

6. Planejamento e estudo das práticas formativas - Antes de entrar em uma reunião formativa, o Coordenador Pedagógico necessita estar preparado para aprofundar e tematizar conhecimentos, isso vai auxiliar o corpo docente a apreender melhor o objeto de ensino, assim como a maneira de ensinar, para tanto, ele precisa estudar, investigar e planejar (ALMEIDA; PLACCO, 2012).

7. Produção de registros - É fundamental que tudo o que é observado pelo coordenador 
nas salas de aula e analisado nos planos de aula seja registrado por escrito. Tais registros visam à devolutiva para os professores e ajudar no planejamento do próprio Coordenador Pedagógico. Almeida e Placco (2012) apontam o portfólio como uma das formas de organização desses registros.

8. Reunião com alunos e professores - Sempre em parceria com os professores, também é função do Coordenador observar e avaliar os estudantes, para, assim, planejar o apoio pedagógico e/ou "comunicar aos estudantes os aspectos em que precisam melhorar" (AMADO; GOUVEIA, 2012, p. 90).

Segundo Placco (2004), o trabalho do Coordenador Pedagógico deve estar pautado no planejamento que antecede as atividades pedagógicas realizadas pelos professores na escola, ou ainda no acompanhamento e orientação delas. O Coordenador Pedagógico é aquele que prevê, articula, media e avalia as ações pedagógicas da escola com e para o professor.

Ainda nessa mesma linha, Almeida e Placco (2011) afirmam que cabe à Coordenação Pedagógica levantar questões junto ao professorado, levá-los a reflexões sobre sua prática pedagógica em sala de aula. As autoras ressaltam ainda que o Coordenador Pedagógico é aquele que participa da elaboração e/ou adaptação da proposta pedagógica, podendo assim dar novos significados à prática educativa da escola e à prática pedagógica dos professores.

Para tanto, se faz necessária também a formação do Coordenador Pedagógico, para que ele se sinta fortalecido, seguro e capaz para exercer o trabalho para o qual foi escolhido. Essa formação pode vir da Secretaria de Educação ou mesmo da simples troca com pares ou profissionais mais experientes. O Coordenador também faz parte de um coletivo que reflete sobre questões e práticas pedagógicas.

\section{O trabalho do coordenador pedagógico na prática}

Para Vasconcellos (2011), o Professor Coordenador Pedagógico está sempre atento às necessidades dos professores. Ele os acolhe, escuta, subsidia, interage e questiona, provoca e problematiza questões relacionadas às práticas de sala de aula. Isso significa que as ações do professor com seus estudantes perpassam as ações do Coordenador.

Com relação à figura do Coordenador Pedagógico na escola, Placco (2011) apresenta três visões possíveis:

1. Aquele que representa os objetivos e princípios da rede escolar em que atua;

2. $\quad$ Educador que tem como obrigação oferecer formação aos professores; 
3. Alguém que tenta fazer valer suas convicções no Projeto Político-Pedagógico da escola.

Dentre as três visões, a segunda é vista pela autora como a de mais complexidade, por envolver ações que objetivam o crescimento pessoal e profissional de pessoas e por entender que, para formar professores, o Coordenador Pedagógico deve estar atento a questões como a cultura dos grupos, valores comuns e diferentes dos indivíduos, relações interpessoais, subjetividade produzida em diferentes contextos de relações.

A escola é o espaço onde se reproduz e ao mesmo tempo se transforma a sociedade e a cultura (PLACCO, 2006). Da mesma forma, as práticas dos docentes nas escolas também apresentam dialéticas e pontos de vista que são defendidos e, logo depois, contraditos. Faz parte do trabalho dos Coordenadores Pedagógicos expor e deixar explícitas as contradições que estão por trás de tais práticas, para que haja um crescimento profissional para os professores e, consequentemente, uma transformação positiva em suas aulas.

De acordo com Orsolon (2006), para que o Coordenador possa atuar como um agente produtor de mudança, no que tange a formação de professores, algumas ações são necessárias:

1. Promover um trabalho de coordenação que esteja conectado com a organização/gestão escolar

Quando o grupo de professores percebe que há uma interação/relação no trabalho da equipe escolar como um todo, em que as ações pedagógicas e administrativas conversam entre si e, mais, quando a gestão da escola é democrática e participativa, com a possibilidade de que todos se envolvam, isso resulta na construção de uma escola em que as relações e os planejamentos de trabalho podem se dar de maneira menos compartimentada tornando-se assim mais compartilhada e integrada (PLACCO, 2006).

\section{Realizar um trabalho coletivo, integrado com os atores escolares}

Se há a necessidade de mudança na escola, o primeiro passo é trabalhar coletivamente, entender que ações fragmentadas e individualizadas não promovem transformações. $O$ Coordenador, como um dos articuladores desse trabalho coletivo, deve ser capaz de ler, observar e reunir as necessidades dos que atuam na escola (PLACCO, 2006) e, a partir disso, introduzir inovações, para que todos se comprometam com o que foi proposto. 


\section{Mediar a competência docente}

A função mediadora também é do Coordenador Pedagógico e, para que essa mediação seja na direção da transformação, é importante que este considere e valorize o saber, as experiências, interesses e modo de trabalhar de cada professor (PLACCO, 2006), bem como criar condições para questionar essa prática e disponibilizar recursos para modificá-la.

\section{Incentivar práticas curriculares inovadoras}

É tarefa do Coordenador Pedagógico propor aos professores novas práticas. Porém, esse trabalho não é fácil, pois conduz a um momento de criação conjunta, ao exercício da liberdade e às possibilidades de parceria. De acordo com Placco (2006, p. 23):

Acompanhar esse trabalho possibilita desencadear um processo de reflexão na ação (formação continuada), durante o qual o professor vivencia um novo jeito de ensinar e aprender e, mediante essa nova experiência, revê sua maneira de ser e fazer, pois a inovação incide em sua pessoa e em sua atividade profissional.

\section{Investir na formação continuada do professor na própria escola}

Uma das funções do Coordenador é propiciar formação aos professores na própria escola, esses momentos normalmente ocorrem em Horários de Trabalho Pedagógico Coletivo (HTPC) e Reuniões Pedagógicas. Esse trabalho dá ao professor condições para que ele faça de sua prática objeto de reflexão e pesquisa, além de leva-lo a problematizar suas ações, transformando-as (PLACCO, 2006).

6. Estabelecer parceria com o aluno: inclui-lo no processo de planejamento do trabalho docente

A escola existe para e pelo estudante e, para que ela possa alcançar seu objetivo de formá-lo, é fundamental que ele seja um dos agentes mobilizadores da mudança do professor (PLACCO, 2006). Dessa forma, o Coordenador precisa encontrar meios de possibilitar ao aluno a participação ativa na construção do currículo da escola, seja com opiniões, sugestões e até mesmo avaliações. Além disso, o professor obtém maior conhecimento de seus estudantes e vivencia posturas de flexibilidade e mudança.

\section{Criar oportunidades para o professor integrar sua pessoa à escola}

Um dos maiores problemas da educação é a fragmentação, seja no currículo, nas disciplinas, na equipe gestora da escola e assim também é com o professor. O que ele é 
(pessoal) não deve estar desvinculado do que ele faz (profissional), e cabe ao Coordenador Pedagógico proporcionar espaços e situações para que eles possam compartilhar suas experiências e se posicionarem enquanto cidadãos e profissionais que são (PLACCO, 2006).

\section{8. $\quad$ Procurar atender às necessidades reveladas pelo desejo do professor}

No planejamento da Coordenação, devem constar os desejos e anseios dos professores. Assim, o Coordenador encontrará uma situação propícia para realizar ações transformadoras na escola.

\section{Estabelecer parceria de trabalho com o professor}

Conforme Placco (2006), embora pareça óbvio dizer que os trabalhos do Coordenador Pedagógico e do professor acontecem em parceria, parece necessário pontuar que essa dinâmica, quando realmente ocorre, possibilita ações e tomada de decisões que podem garantir o alcance dos objetivos estabelecidos.

\section{Propiciar situações desafiadoras para os professores}

Quando o professor se sente desafiado, ele sai da situação cômoda em que muitas vezes se vê e passa a se sentir instigado a buscar novas ideias, novos estudos, novos olhares e, consequentemente, novas ações. E é por meio do acompanhamento das ações do professor que o coordenador vai poder desafiá-lo e com isso "Desencadear um trabalho de acompanhamento da ação docente, que privilegie a reflexão crítica da prática do professor, movimenta-o para a mudança [...]” (PLACCO, 2001, p. 26.)

Quando professores e coordenadores atuam juntos, nas decisões que irão direcionar as ações pedagógicas na escola, equívocos são reparados e existe maior e mais aprofundada reflexão das atividades antes destas serem direcionadas aos estudantes. Desse modo, o processo de formação dos professores está relacionado às suas práticas. Muitos coordenadores reconhecem que é importante discutir com os professores as ações que serão realizadas com os discentes, "julgam necessário conhecer como ocorrem, nas salas de aula, as relações de ensino e aprendizagem, principalmente no que se refere ao modo como o professor encaminha a interação da criança com o conhecimento" (PLACCO, 2001, p. 57). 


\section{Considerações finais}

À medida que as reflexões foram se articulando, a autora se inquietava e se interessava mais profundamente pelo trabalho em questão, isso se deu devido ao fato de ser ela Coordenadora Pedagógica e fez com que refletisse acerca da aplicabilidade desse estudo na escola em que atua. Isso significa que este artigo é um marco de uma sintética transformação no processo formativo, de quem vos escreve e reflete através das leituras, almejando transpassá-las da maneira mais explícita possível

Diante do exposto, podemos verificar o quanto o trabalho do coordenador pedagógico é fundamental dentro da escola e, ao mesmo tempo, a existência dos impasses que dificultam o desempenho pleno de suas atribuições enquanto formador de professores e articulador do projeto político-pedagógico da escola, como mediador de situações de conflito ou ser levado a executar tarefas que não dizem respeito à sua função.

Nesse aspecto, é fundamental que ele tenha um planejamento e que estabeleça uma rotina de trabalho para que consiga atingir os objetivos que estabeleceu e realizar as atividades que de fato são parte da sua atribuição.

Da mesma maneira que os professores formam os estudantes fazendo a mediação do conhecimento, o coordenador pedagógico é quem forma o professor dentro da escola, faz a problematização do que é ensinado aos discentes em sala de aula e auxilia na reflexão sobre suas ações, a tão conhecida práxis.

À medida que o coordenador pedagógico traz subsídios teóricos para as formações, faz devolutivas a respeito de aulas que assistiu ou observações acerca de planos de aula que analisou, faz questões provocativas quando observa necessidade, contribuindo com a práxis docente do grupo de professores na escola.

Entretanto, como já dito, o coordenador deve estar atento a questões como a cultura dos grupos, valores comuns e diferentes dos indivíduos, relações interpessoais, subjetividade produzida em diferentes contextos de relações, para que, além disso, ele deixe de ser visto como aquele que está lá para vigiar ou inspecionar (visão presente até hoje nas escolas). O professor precisa vê-lo como um parceiro, alguém que pode solicitar ajuda. Essa confiança é adquirida com o tempo, a cada fala, escrita e ação cuidadosa e respeitosa do Coordenador Pedagógico para com seus professores e demais atores sociais que fazem parte do contexto escolar. Assim, certamente a recíproca será verdadeira e, mais do que ninguém, quem sairá ganhando é o estudante. 


\section{REFERÊNCIAS}

ALMEIDA, L. R. Um dia na vida de um coordenador pedagógico de escola pública. In: PLACCO, V. N. S.; ALMEIDA, L. R. (Org.). O coordenador pedagógico e o cotidiano da escola. 9. ed. São Paulo: Loyola, 2012.

ALMEIDA, L. R.; PLACCO, V. M. N. S. (Org.). O coordenador pedagógico e as questões da contemporaneidade. São Paulo: Loyola, 2006.

ALMEIDA, L. R.; PLACCO, V. M. N. S. (Org.). O coordenador pedagógico e o espaço da mudança. 6. ed. São Paulo: Loyola, 2007.

ALMEIDA, L. R.; PLACCO, V. M. N. S. (Org.). O coordenador pedagógico e o cotidiano da escola. São Paulo: Edições Loyola, 2003.

AMADO, C; GOUVEIA B. Coordenador pedagógico: função, rotina e prática. Palmeiras, BA: Instituto Chapada de Educação e Pesquisa, 2012.

BRASIL. Lei n. 9.394, de 20 de dezembro de 1996. Lei de Diretrizes e Bases da Educação Nacional (LDB). Diário Oficial da União, Brasília, DF, 23 dez. 1996. Disponível em: www.planalto.gov.br/ccivil_03/leis/L9394compilado.htm. Acesso em: 15 nov. 2017.

BRASIL. Ministério da Educação. Base Nacional Comum Curricular (BNCC). 2. versão. Disponível em: basenacionalcomum.mec.gov.br. Acesso em: 11 dez. 2017.

FERNANDES, M. J. S. O professor coordenador pedagógico e a fragilidade da carreira docente. Estudos em Avaliação Educacional, São Paulo, v. 20, p. 411-424, 2009. DOI: https://doi.org/10.18222/eae204420092037

LIMA, P. G; SANTOS, S. M. O coordenador pedagógico na educação básica: desafios e perspectivas. Educere ET Educare, Cascavel, v. 2, n. 4, p. 77-90, jul./dez. 2007. Disponível em: www.ufgd.edu.br/faed/nefope/publicacoes/ocoordenador-pedagogico-naeducacao-basicadesafios-e-perspectivas. Acesso em: 15 jun. 2020.

ORSOLON, L. A. M. O coordenador/ formador como um dos agentes de transformação da/na escola. In: ALMEIDA, L. R.; PLACCO, V. M. N. S. (Org.). O coordenador pedagógico e o espaço de mudança. 5. ed. São Paulo: Loyola, 2006.

SILVA, M. A. Intervenção e consentimento: a política educacional do Banco Mundial. Campinas, SP: Fapesp, 2002.

SILVA, M. A. Do projeto político do Banco Mundial ao projeto político-pedagógico da escola pública brasileira. Cadernos CEDES, Campinas, v. 23, n. 61, p. 283-301, dez. 2003. Acesso em: 01 jun. 2020. DOI: https://doi.org/10.1590/S0101-32622003006100003

VASCONCELLOS, C. S. Coordenação do trabalho pedagógico: do projeto políticopedagógico ao cotidiano da sala de aula. São Paulo: Libertad, 2007.

VENAS, R. F. A transformação da coordenação pedagógica ao longo das décadas de 1980 e 1990. In: COLÓQUIO INTERNACIONAL EDUCAÇÃO E CONTEMPORANEIDADE, 6. 
2012, São Cristóvão. Anais eletrônicos [...]. São Cristóvão, SE: EDUCON, set. 2012. Disponível em: educonse.com.br/2012/eixo_17/PDF/47.pdf. Acesso em: 25 jun. 2020.

\section{Como referenciar este artigo}

SILVA, A. A. Coordenadores pedagógicos: trajetória, competências e responsabilidades. Revista on line de Política e Gestão Educacional, Araraquara, v. 25, n. 1, p. 38-51, jan./abr. 2021. e-ISSN:1519-9029. DOI: https://doi.org/10.22633/rpge.v25i1.13983

Submetido em: 24/05/2020

Revisões requeridas em: 28/07/2020

Aceito em: 10/09/2020

Publicado em: 02/01/2021 